Please note this text is the author's accepted manuscript. It is not the final published version of the paper.

Orrego-Carmona, David (2018) "New audiences, international distribution, and

translation" in Elena di Giovanni and Yves Gambier (eds) Reception Studies and

Audiovisual Translation. Amsterdam: John Benjamins Publishing Company. 321-342. DOI:

https://doi.org/10.1075/btl.141.16orr

\title{
New audiences, international distribution, and translation
}

\author{
David Orrego-Carmona \\ Aston University, Birmingham, United Kingdom \\ University of the Free State, Bloemfontein, South Africa
}

\begin{abstract}
The interconnectivity made possible by the technological advancements of the past three decades has changed the way how audiences engage with audiovisual content around the world. On the one hand, viewers have become empowered consumers who are also engaged in the distribution of content; on the other, companies serving global audiences have emerged as key players in the audiovisual market. With more access to content, through piracy or official channels, new consumption habits, such as binge watching, have become common among viewers. Non-professional subtitling has played a key role in the expansion of the audiovisual market, the configuration of international audiences and the development of new viewing traditions. By looking at non-professional subtitling as a constituent of the international media flows, this chapter proposes Translation Studies should look at the reception of non-professional subtitles at a global scale to understand the interplay between non-professional subtitling, its producers/users and the audiovisual market, as well as the societal impact of the phenomenon.
\end{abstract}

Keywords: binge watching, piracy, convergence, non-professional subtitling, reception

Since its inception in the last century, television and the form of entertainment that it provides

have morphed significantly, mostly due to the thriving development of the technology that makes

it possible. Nowadays, watching television has expanded to become an overarching experience

that occurs across platforms, media and resources engaging various social, technological and

human agents at a globally interconnected level. In the world of transmediality, newspapers and 
journals comment on products before they are released; products include references to other products and to pop culture; people talk about them on Facebook, Twitter, and Reddit, post screenshots on Instagram, discuss them in blog entries, etc. This sets the tone for the media convergence described by Jenkins as a cultural shift that represents "the flow of content across multiple media platforms, the cooperation between multiple media industries, and the migratory behavior of media audiences who will go almost anywhere in search of the kinds of entertainment experiences they want" (2006a:2). The viewers or consumers of audiovisual products who make up the audience have become empowered consumers (Bold 2011), engaged both in the production and consumption of audiovisual products. The audiences of these new media products have become emotionally invested in the content and have moved from the traditional role of consumers to an active role of prosumers, viewers who enact characteristics both of the consumption and production of the audiovisual content (Tapscott \& Williams 2006).

The growth of the participatory culture has had a major impact on the configuration of international audiences (Jenkins 2006b). Realizing the power that technology gives them, fans took it upon themselves to create parallel distribution networks at a global scale. Fans defy the status quo and enlarge the circulation of the audiovisual products they love. Fan networks do not recognize linguistic, geographical or political boundaries, and allow for the global distribution of audiovisual content through the Internet. As part of this intensified connectivity-more active flows of content and faster exchange- language becomes a key enabler for the communication and transfer of information. The increased circulation of audiovisual products has made it possible for viewers, fans, and occasional viewers to have access to large archives of video content without the need of relying on national broadcasters. Regardless of their location, viewers just need a working Internet connection to access these repositories. As a result, they 
started to consume more content, and companies, such as Netflix and Amazon, quickly picked up and started to adapt their market strategies to respond to the immediacy needs of these consumers. Binge watching -watching several episodes of TV shows in rapid succession- has become a standard practice for millions of consumers all around the world.

Fan communities have been at the core of these changes and non-professional subtitles have played an essential role in the circulation of audiovisual material at a global level. However, little has been done to relate the Translation Studies discourse to the media convergence phenomenon (Pérez-González 2013). This chapter offers a broad overview of the circumstances that have paved the way for new audiovisual consumption traditions to emerge. It highlights the importance of exploring the reception of translation and the benefits for Translation Studies to fully integrate reception research as a way of understanding translation users and the impact of translation as a non-professional practice.

\section{The empowerment of users}

Prior to the Internet era, broadcasters had the power to decide about programming and scheduling, and viewers received the packaged content. At the time, viewers had the choice of deciding whether to watch the content or not, but their power of choice was extremely limited within the possibilities that broadcasters granted them. However, the rise of the participatory culture and the media convergence that has been unfolding since the 1980s, starting with fandom movements and later with larger groups of users, has radically changed the nature of audiences (Jenkins 2006a). The new media environment involves engaged and empowered consumers who 
have understood that technology can be put at their service to achieve their goals. As a consequence, media companies have realized they need to keep up with the pace of the audiences' expectations and promote innovation to cater for their users.

Audience engagement is vital for audiovisual products in the globalized and digitalized market. On the one hand, the media industry depends heavily on its capacity of capturing the audience's attention and convincing its viewers that the products they are offered are worth the emotional and financial investment required. The industry needs to attract and maintain their audiences' attention. On the other hand, these viewers have become more critical and demanding regarding what they expect from the products. Viewers have gained the power of creating their own viewing schedule and developing new consumption patterns that better suit their needs and wishes. With many more products at their disposal, they have become more selective in terms of what they watch and what products are worth their time, efforts and resources. Whether they use this power or not is also their decision and many viewers still follow appointment viewing and use traditional TV channels, but the trends seem to indicate that viewers, and especially younger audiences, are moving more and more towards video-on-demand (VOD) services. Nearly twothirds of global respondents $(65 \%)$ in a Nielsen online survey in 61 countries say they watch some form of VOD programming (The Nielsen Company 2016), but most of these viewers use VOD as a supplement to traditional television (cable) and not as a replacement.

Currently, more intricate plots, with surprises and twists, are necessary to keep the eager audiences' interest and give them space to expand the fictional universe and create additional content of their own. Exploring reception is becoming more important than ever because audiences expect to have their expectations fulfilled in order to engage with the content. They have the need to speculate about what might happen in their favorite shows, they welcome 
opportunities to participate in discussions about how the events will unfold and how the fictional worlds are built. While or after watching an episode, engaged viewers turn to Twitter and Reddit to discuss the clues left behind. Shows like Game of Thrones and Westworld, which still use appointment viewing, count on this. Fans use the time between episodes and seasons to create their own theories piecing together the clues that producers slip into the narrative. Engaged viewers make the shows part of their lives and experiences.

Viewer engagement goes beyond the active consumption of the content. Active and occasional viewers become involved in the production and consumption of user-generated content that is developed to deepen and enlarge the fictional universes in which the audiovisual products unfold (Jenkins 2006a; Mittell 2009). Through remediation (Denison 2011) and extension practices, engaged audiences interact online in discussions, forums, social media and websites dedicated to the content of their preference. These viewers are used to invest the resources they have at their disposal "to improve and amplify their viewing experience through technological devices that transcend the television medium itself' (Casarini 2014b:n.p.). Content can always be expanded, reshaped, amended and corrected, by producers (through remakes, revivals, cross-overs, accompanying websites, social media presence, etc.) or by any of the forms of distribution by users or the creation of user-generated content. This continuum of the creation process and constant expansion of the products through different media give (audiovisual) texts an aspect of non-finiteness (Gambier 2016).

The spectrum of possibilities through which active viewers can engage with the content is ample and varied. They have assimilated these dynamics and developed patterns of consumption that depart from those pre-conceived by the producers. They come up with independent and innovative modes of consumption of their own. They watch more content, and do so in rapid 
succession, they talk about it online, create tributes, share it with friends, translate it for increasing circulation and come up with parody translations, create more content based on the original one. This creates a situation in which users are, at the same time, consumers and producers of translations (Cronin 2012). In these contexts, translation can take different forms and roles and it becomes essential to explore the reception of these works to understand how the new audiences receive, perceive and conceive translation.

\section{Piracy, media consumption, and audiences}

Piracy has been key in the configuration of global audiences and the creation of international networks of viewers. One way in which the users have assumed the role of producers and broadcasters is by illegally distributing TV shows and films online. Karaganis (2011b) uses the term piracy "to describe the ubiquitous, increasingly digital practices of copying that fall outside the boundaries of copyright law" (2011b:2). Reaching a stable definition of piracy is not a simple issue given that it entails legal and sociological considerations. Such discussions fall out of the scope of this chapter; here, the term piracy is used to refer to the copying and distribution of audiovisual content "uploaded, downloaded, or shared on the Internet" (Ballano 2016:25).

Although initially it did not receive as much attention as music and movie piracy, the increase in television piracy has made companies more concerned about it in recent years. In many senses, the television industry fears the dark past of the music industry and its failed war against Napster and music piracy in general. It is fair to say that these fears are not completely unjustified. In recent years, thanks to better Internet connections, piracy has increased steadily 
and created an alternative market that many users consider legitimate. For instance, TorrentFreak reports that Game of Thrones has been the most pirated show through peer-to-peer (P2P) between 2012 and 2015. ${ }^{1}$ In 2015, Game of Thrones had 14.4 million illegal downloads, surpassing the 8-million estimate of legal viewers per episode in the US. ${ }^{2}$ The series was the most pirated show in 2016 again, but as of 2016 TorrentFreak stopped reporting download estimates due to changes in the torrent indexing system. ${ }^{3}$ Game of Thrones is not an exception. In many cases, the number of downloads of a show via Torrents surpasses the estimated number of legal viewers in the US. The P2P data should be taken only as a proxy indicator of the reach of piracy. The figures do not account for streaming websites, file lockers and other types of illegal distribution of content. It is safe to assume figures are actually higher.

Piracy has created a parallel consumption environment for audiovisual products, with an emerging global spectatorship that has its own dynamics and exhibits characteristic behaviors. New media consumption habits thrive in these alternative, parallel markets. People can consume more through piracy because more content is available to them and it comes at a fixed price. DVDs or services such as iTunes charge per episode or film, and services like Netflix, Amazon Prime or Hulu have large but limited libraries due to the limiting conditions of licensing deals and geographical restrictions. On the contrary, unauthorized online archives can create large libraries because they rely on the indexing of any online video sources and can operate at a global scale. The repositories provide immediate access to organized archives which are updated hourly by prosumers (Bruns 2009).

\footnotetext{
1 “Game of Thrones most pirated TV-show of 2015” https://torrentfreak.com/game-of-thrones-most-pirated-tvshow-of-2015/

${ }^{2}$ https://en.wikipedia.org/wiki/Game_of_Thrones

${ }^{3} \mathrm{https}: / /$ torrentfreak.com/game-of-thrones-most-torrented-tv-show-of-2016-161226/
} 
The availability of content also makes it is easier for users to watch more content. Comparing the case of NBC video content in iTunes and Amazon.com in the US, Danaher et al. (2010) found that when there are no legal means to access audiovisual content, even purchasers can turn to piracy, which not only generates a jump in the total number of downloads but also causes individuals to consume "more content through piracy than they had previously purchased" (2010:1149). Piracy requires users to invest a combination of economic capital (internet connection, hardware) and social capital (time, knowledge regarding the how-to of piracy, dealing with the stigma and moral costs). However, these costs come at a fixed price: once a person has acquired the setup and knows how to access the content, additional downloads come at a marginal price and it is thus easier to access more content. This has allowed piracy to have a strong impact in emergent economies where users have a limited amount of monetary resources to access entertainment and are used to informal economy arrangements (Mattelart 2013). The piracy culture (Castells \& Cardoso 2013) constitutes an essential part of our current networked society and showcases the social differences exhibited by the members of said network because it makes all agents, regardless of their social status, condition or role in the economy, interact in the same global space. The two collective volumes, Karaganis (2011a) and Castells \& Cardoso (2013), serve as examples of the expansion and impact of piracy not only in Europe and the US but also in Africa, Latin America, Asia, and Oceania.

Piracy started as a grassroots movement for users to make up for the lack of distribution and delayed international releases. However, "streaming media and downloadable videos can no longer be considered as poor cousins of broadcast” (Bruns 2009). According to MUSO's Global Film \& TV Piracy Insights Report 2016, ${ }^{4}$ there were 78.5 billion visits to film and television

\footnotetext{
${ }^{4}$ https://www.muso.com/magazine/press-release/musos-global-film-tv-piracy-report-2016-released/
} 
piracy websites in 2015 . The survey tracked the traffic from 14.000 of the largest piracy websites in 240 countries. Pirate-distribution websites have become user-friendly and cater for multiple audiences, from those who have poor connections and want to access low-image-quality content to those who want high-definition versions of the products. According to Kosnik, "piracy is the easiest, simplest, most feature-rich means available for acquiring TV by means of the Internet" (2010:16).Once users have access to Torrents, file lockers or other streaming platforms, piracy becomes first and foremost a convenient form of accessing audiovisual content.

Unauthorized channels of distribution are more malleable than those of official media. Piracy creates more room for the participatory culture to flourish and spawns new forms of engagement. The online formats used by unauthorized distribution networks are well suited for the consumer-led disruption and co-creation since they are not protected and can be re-used in online websites and social media. Additionally, since the platforms depend on the user's decisions, they can answer users' requests more readily. Unauthorized distribution websites open possibilities for viewers to explore and transgress boundaries. In this environment, viewers, especially fans, gain the right to remediate the content and become part of something larger. The technological boost that prompted the disruption of television consumption among audiences provided fans with more power, which translated into visibility:

\footnotetext{
"Fans have always been early adopters of new media technologies; their fascination with fictional universes often inspires new forms of cultural production, ranging from costumes to fanzines and, now, digital cinema. Fans are the most active segment of the media audience, one that refuses to simply accept what they are given, but rather insists on the right to become full participants. None of this is new. What has shifted is the visibility of fan culture. The web provides a powerful new distribution channel for amateur cultural production. Amateurs have been making home movies for decades; these movies are going public.” (Jenkins 2006a:131-132)
} 
The main difference for the configuration of the audiences is that the convergence culture does not only include the active fans, but also the occasional viewers and every other person that directly or indirectly relates to the content: everyone is a participant, although there are different degrees of involvement and influence, as commented above (Jenkins 2006a). The massification of the distribution of audiovisual content has created networks of people who consume more content, and faster than ever before. Not all of them can be considered the traditional hardcore fans, who make characters and TV series part of their everyday lives, but all of them engage directly or indirectly with the content being distributed and are affected by the peroducers' decision. For instance, not all users might engage in pushing companies to reduce the delays in international distribution, but all consumers in the international markets eventually benefit from early releases. The larger share of the audience that consumes the content produced by the actively engaged viewers or is affected by their actions is, in the end, the raison d'être of the whole phenomenon.

\section{Binge watching: from piracy to Netflix}

The impact of the users' empowerment and their involvement in piracy has, as we have already seen, partly reshaped media consumption habits and contributed to the formation of new audiences. Binge watching, the practice of watching multiple episodes of a TV show back to back over a short period of time, has gained momentum in recent years. It emerges as a result of the technological democratization and the viewers' autonomy; it leaves behind appointment viewing and grants users power over the type of content they watch, the time when they watch it, and the form in which they want to watch it. 
Commonly, binge watching is seen as an effect of the Netflix era. The global streaming company has made bulk releases an essential part of its brand strategy; in so doing, it has put binge watching at the forefront of the consumption behavior of VOD users. Netflix has a global reach, offers a large and well-curated archive of audiovisual content and presents users with a user-friendly platform equipped with algorithms that offer personalized suggestions. These features have made Netflix a perfect player to bring binge watching to the general public. Currently, Netflix has about 100 million subscribers globally and Amazon Prime has at least 66 million. Both of them added about 20 million users in the last year only, following global expansion strategies. VOD viewers have welcomed and embraced binge watching practices. Reporting on a global survey conducted in 2015, Nielsen comments that "two-thirds of global VOD viewers say they watch multiple episodes in a single sitting." published in 2017 found that $73 \%$ of US viewers binge watch, especially young adults. ${ }^{6}$

However, binge watching as a behavior of the international viewership finds its roots in the informal media systems that appeared soon after the popularization of the Internet. Since the early 2000s, unauthorized video distribution websites have been presenting users with archives of audiovisual content they can access, granted they have the adequate hardware and a working Internet connection. YouTube served for this purposes in the 2000s, when it was possible to occasionally find entire episodes and seasons of popular shows on the platform ${ }^{7}$ (Kosnik 2010). Piracy networks pre-date official distribution channels in most aspects which are characteristic of

\footnotetext{
${ }^{5}$ http://www.nielsen.com/uk/en/insights/news/2016/binge-bunch-two-thirds-of-global-vod-viewers-say-they-watchmultiple-episodes-per-sitting.html

${ }^{6} \mathrm{http} / / /$ www.prnewswire.com/news-releases/deloitte-73-percent-of-americans-binge-watch-tv-millennial-bingewatchers-average-six-episodes-and-five-hours-per-viewing-300427152.html

${ }^{7}$ It is still possible to find full episodes of shows on YouTube, but mostly of older or minor productions or productions from countries where copyright is not strongly enforced. Additionally, creators have started to rely on YouTube and Vimeo, among other platforms, to launch their independent products in the form of web series. The web series act as a showcase that attracts the attention of big networks. This was the case of High Maintenance and EastSiders, which were later picked up by $\mathrm{HBO}$ and Netflix, respectively.
} 
online video consumption. Inherently, they give viewers more freedom regarding their consumption behaviors. New TV viewing practices are founded on the need to access highquality content at any time the users wish. The repositories created by piracy networks provide vibrant conditions for the emergence of new consumption practices that respond to the needs of the audiences. For instance, these platforms test the long-tail distribution model based on the exploitation of content over time: selling less of each product, but offering more products at the same time (Anderson 2006). It was this phenomenon that inspired the rapid evolution of VOD platforms.

The growth of video on demand as a distribution method serves as an example of the influence that piracy networks have on legal distribution channels. Netflix, Amazon Prime, Hulu, and HBO Go are examples of services that have adopted mechanisms inspired by the grassroots movements to serve the new needs of the viewers and adapt to the changing market. And this also includes the new roles of translation. Non-professional subtitling has been the strategy adopted by piracy networks to translate the content they distribute, as a way to increase the reach of the networks by covering a larger target audience. Netflix, HBO Go, other streaming services and even traditional channels have also started to rely more and more on subtitling to ensure that the international distribution of their content is not delayed by the time required to produce the translations. Even in traditionally dubbing countries, the industry has tried subtitling as an option to release audiovisual content at the same time or shortly after its original broadcast. Movistar in Spain, ${ }^{8}$ Canal+ in France ${ }^{9}$ and Sky in Italy, ${ }^{10}$ for instance, have started to use subtitling to release

\footnotetext{
${ }^{8} \mathrm{http}: / /$ www.lavanguardia.com/series/20160422/401278469175/juego-de-tronos-como-donde-ver-canal-plusseries.html

${ }^{9} \mathrm{http} / / /$ www.20minutes.fr/television/1292942-20140101-series-diffusees-24h-apres-us-course-usante-auteurs-soustitres

${ }^{10} \mathrm{http}: / /$ www.ilpost.it/2016/05/23/game-of-thrones-streaming/
} 
the new episodes of popular TV series, such as Game of Thrones, only a couple of hours after their original release in the US.

Binge watching also changes the degree of engagement with the content, since the period of consumption of a season, for instance, reduces from two to four months to a couple of days or hours. Consuming audiovisual products in rapid succession allows viewers to develop an intense degree of engagement with the content and bond with the characters and stories very quickly. However, since the run time of the content is limited, viewers quickly go from a period of high degree of engagement to a passive consumption time in-between season when, even if they are still expecting and excited about the upcoming season, viewers do not have any significant input. There is an intensive consumption period for the product that ends up being ephemeral, as the longest seasons last for about 20 hours only and can be as short as five hours in the case of miniseries. Consuming content at this rate implies, initially, a degree of social exclusion. However, there is a social pressure exerted by the internet communities and circles of friends to watch the content as soon as it is made available. Not watching the series once it becomes available means viewers are exposed to spoilers that start appearing on social media, reviews, memes, gifs, etc. Thus, binge watching actually enables social interaction and allows people to engage with other viewers. Since audiovisual content creates a high degree of expectation, immediacy is essential and people have adapted to watch the content shortly after it is made available (Orrego-Carmona \& Richter, forthcoming). With more shows and more interesting shows at the viewers' disposal, binging is quickly becoming a common regime of watching (Matrix 2014). Appointment viewing is still the standard method for the broader part of the industry and it is accepted by the audiences as the traditional mode of distribution, but that does not mean that binge watching and the pressing need of consuming content as soon as it is available is not the preferred practice 
among viewers. Synchronized international releasing events such as the release of the final episode of Lost or the highly expected releases of Game of Thrones indicate viewers are always in a hurry to consume content. However, variety seems to be the key. Netflix itself is currently experimenting with the weekly release of episodes for series it buys from other networks and studios, following the traditional mode of distribution.

Binge watching is a good example of how the audience's empowerment has influenced traditional media, significantly changing how people relate to audiovisual content. The strategies put in place by companies such as HBO and the steadily growing numbers of Torrent downloads confirm that it is unlikely that piracy will stop (Strangelove 2015). Piracy has been so disruptive for traditional media because it has evolved outside of the mainstream industry's control, while still influencing it heavily and, in some cases, dictating what traditional media should do to accommodate the new audiences.

\section{The role of translation: from fansubbing to non-professional subtitling}

In a globalized and interconnected world, language is a barrier to the consolidation of a digital globalized culture, as is attested to by the search for fully automated machine translation that aims at streamlining the translation process. Solving the issue of linguistic barriers has been an intrinsic challenge for media convergence and the participatory culture since the very beginning of the fandom phenomenon (Jenkins 1992:78). To distribute audiovisual content through unauthorized channels across borders and cultures, the language problem needed to be addressed. Fans who assumed the task of archiving, transferring and circulating content across countries and regions were faced with language barrier issues and needed to resort to creative ways for dealing 
with them: group screenings with live interpreting, fansubbing, fandubbing, scanlation (Jenkins 2006a). Translation has been inherently embedded in the expansion of media convergence, and it constitutes an essential part of the participatory culture. However, it has not been properly addressed in studies dealing with the participatory culture. On the one hand, linguistic issues are normally only mentioned in passing by media scholars. On the other, only recently have Translation Studies scholars started to embed the discussion on non-professional subtitling within a wider framework that accounts for media convergence and the participatory culture. As Pérez-González explains, "for all the similarities that exist between amateur subtitlers and other types of 'prosumers', the contribution and involvement of reflexive consumers in the translation of audiovisual global flows remains vastly underexplored" (2013:166).

Translation, in its broader sense involving interlingual and intralingual mediating actions, is one of the forms active users have taken on in their commitment to remediate and circulate content (Pérez-González 2013) through unauthorized networks. Non-professional subtitles are produced by highly committed users who dedicate time to create subtitles and distribute them over the Internet. These users are organized in online communities that vary in size and purpose but share their reliance on technology and commitment to producing and distributing subtitles. When looking closely at online communities, it has been shown that the ratio between production and consumption in online communities is highly skewed: in every online community, only a minority of the members is actively engaged in the production of any type of content (Nielsen 2006; Sun et al. 2014; Yang et al. 2016). The idea of the reflexive consumer is closely related to this more actively engaged minority: reflexive consumers are the ones committed to the translation and distribution of videos and subtitles. However, in the communities, the majority of the members lurk, they consume the content that is made available 
to them by the more actively engaged members. Subtitles can be produced by individual active viewers or small groups of four or five people, but they can be accessed and used by much larger groups of active viewers who purposefully look for them online. These different degrees of commitment and collaboration are part of the expansion of the prosumers' activities since they engage with the communities by consuming their products. Even though lurkers do not produce content, they are still essential for the prosumer activities to make sense and are active viewers engaged in the increased circulation of translated audiovisual content. Up to now, this dimension of the societal impact of non-professional subtitling on the reception of audiovisual products has not been properly addressed in Translation Studies.

Research on fansubbing has increased significantly in the last fifteen years, highlighting the relevance gained by the subject. As would be expected, it has developed within audiovisual translation studies, and researchers have primarily adopted case studies as the methodology to explore the phenomenon (Casarini 2014a; Chu 2012; Luczaj et al. 2014; Massidda 2012; Mendes Moreira De Sa 2014; Orrego-Carmona 2016b; Tian 2011). This allows for the exploration of different domains and contexts. However, although the in-depth analyses offered by case studies have been useful and opportune, the projects are usually small and do not allow for generalization (Gambier \& Ramos Pinto 2016). Thorough case studies are, by norm, small, more so if we take into account that most of them are carried out by individual researchers with limited time and resources. Apart from this issue, which affects the discipline in general rather than just the studies on non-professional subtitling, the study of fansubbing and volunteer translation in Translation Studies should recognize and try to overcome two additional challenges: a reductionist take on fansubbing that focuses mostly on anime fansubbing, and the lack of attention to the social implications of non-professional subtitling. 
In academic circles, it is still common to subsume non-professional subtitling activities under fansubbing. The Translation Studies community has stressed the transgressive approach that some fansubbing groups adopt in their work. However, a general understanding of nonprofessional subtitling as transgressive in formal terms and as attached to anime translation and innovation has produced a skewed understanding of the fan subtitling phenomenon as a whole: "This anime-centrism has tended to produce a somewhat lopsided view of the fansubbing landscape, emphasizing its formal and textual difference to mainstream, commercial [audiovisual translation] while downplaying its heterogeneity and geopolitical complexity" (Dwyer 2012:219).

Broadening the understanding of non-professional subtitling is a profound need. Apart from the formal aspects, another assumption that is commonly made is that non-professional subtitling is, by nature, source oriented. While this is true in most cases of fansubbing of anime, due to the users' interests in the Japanese culture, other forms of non-professional translation tend to be more oriented towards the target culture as a strategy to increase acceptability (Chang 2017; Chu 2012). Recent studies, mainly dealing with non-professional subtitling in China, highlight these approaches to translation. The last years have seen the scope broadened from the anime-centered study of fansubbing to exploring fansubbing in a larger sense, thus representing the heterogeneity of the phenomenon (Casarini 2014a; Chu 2012; Luczaj et al. 2014; OrregoCarmona 2016a). Nevertheless, the broader community of users of non-professional subtitles, the lurkers, is still missing in the academic discussion.

Translation Studies scholars have been more focused on the producers of the subtitles, the ways in which the fan-made subtitles challenge the previously established guidelines of subtitling, and the activities of heavy contributors rather than the societal impact of the non- 
professional subtitling phenomenon. Due to the size and variety in non-professional subtitling, it is necessary to broaden the focus to include the users and societal impact of the phenomenon. Current studies show we are moving away from the concept of fansubbing, implying the traditional idea of committed fans and closed communities, to a concept of non-professional subtitling involving all forms of subtitles created by volunteers (Chaume 2013; Jiménez-Crespo 2017; Luczaj et al. 2014; Olohan 2014). Within this framework, we might open space for exploring the users who can find themselves on the consumption side of the participatory culture. Non-professional subtitling is not restrictively performed by fans who feel a special connection with the content they translate. Although traditional fansubbing, particularly the one engaged in the collection, translation, and circulation of anime, has been characterized by a strong fan base that is highly committed to acting as mediators in the distribution process (Díaz Cintas \& Muñoz Sánchez 2006; Pérez-González 2012), studies dealing with other forms of non-professional subtitling have shown that these translation initiatives can be triggered by other factors different from passion for a specific audiovisual product: political activism, being entertained by the task of subtitling as such, increasing media circulation, etc. (Luczaj et al. 2014; Olohan 2014; OrregoCarmona 2016b; Pérez-González 2010).

The broadening of our understanding of the non-professional subtitling phenomenon lets us see non-professional translation as a social phenomenon framed within the participatory culture that has shaped the globalized audiences of media content. The emergence of fansubbing and its growth into full-fledged non-professional subtitling can help us appreciate the impact of reflective communities of viewers and the democratization of technologies. The actions of the active members of these audiences have repercussions affecting not only the members of the communities who use the subtitles of the active users but also the people who are related to the 
content at other levels, even outside the piracy circles: producers of the shows, viewers through legal channels, media covering the products, etc.

The consolidation of non-professional subtitling groups, the fan culture and the unauthorized distribution of content has resulted in a continuous exchange between (and the convergence of) mainstream industries and grassroots movements. Due to the fluidity of media and the demanding behavior of the audiences, traditional distribution channels and unauthorized distributors simultaneously challenge each other, influence each other and coexist in a complex global system. The race for increasing the speed of distribution of audiovisual content has had a direct impact on international distribution. The media industry, in order to reduce the space for piracy, has decided to shorten the international delays (Karaganis 2011b). In Latin America, for instance, until the last decade, people had to wait for up to six months to see the new seasons of their TV shows. Region-wide channels such as Warner TV, Canal Sony, and Fox now release shows only a couple of days or weeks after the original release, while extremely popular shows such as Game of Thrones and The Walking Dead are often broadcast within hours of their release in the United States

Within this new, emerging and ever-changing scenario, exploring the reception of these products both in professional and non-professional channels will help us understand the pivotal role of translation in the current media flows. Some studies have already started approaching this idea. Using a media convergence and audiovisual translation framework, Casarini (2014a) reconstructs the reception of US TV series in Italy between 1990 and 2014. Casarini makes a special emphasis on "Italy's increasing openness toward subtitling" (2014a:286) based on the impact that the fansubbing of US TV shows has had on the audiovisual landscape of this traditionally dubbing country. At this breaking point in audience engagement, she highlights the 
relevance of scrutinizing whether networks and distributors will be willing to "embrace a type of translation and a broadcast schedule that are better fit to match the needs of a meta-niche audience" (2014a:287).

Also exploring the case of subtitling in a traditionally dubbing country, Spain, OrregoCarmona (2014) shows that there is indeed a part of the audience that welcomes subtitling as a valid and useful type of translation, but there are also those who would prefer to stick to the traditional standard of dubbing. Reporting on the case of the broadcast of a subtitled version of Game of Thrones only 18 hours after its original release by Canal+ Spain, Orrego-Carmona (2014) analyzes the reactions of the audience and their use of Twitter to engage in a discussion among themselves and with the provider. This case shows a divide between those people in the audience who embrace subtitling and those who criticize it, and the fact that they are willing to turn to social media to voice their opinions and complaints to make the service providers aware. Orrego-Carmona (2015) claims that the reception of non-professional subtitles among young audiences does not necessarily differ from that of professional subtitles. Using eye tracking, questionnaires, and interviews, Orrego-Carmona found that the reception capacity of viewers does not differ significantly depending on the type of subtitling. The participants in the study make conscious decisions about when to use dubbing and when to use subtitling, depending on aspects such as familiarity with the translation type, the need for multitasking or the social conditions under which the watching experience occurs.

Building on previous studies that explore the motivations of fansubbers (Fernández Costales 2012; Olohan 2014), Duraner et al. (2017) analyze not only the motivations of fansubbers but also those of the users of subtitles in the fansubbing community. They found that fansubbing served as a link to connect Turkish audiences interested in Korean dramas. 
Furthermore, the "translation traffic that started with Korean dramas has paved the way for other products such as Korean pop music, food, and actors to enter the Turkish culture repertoire" (2017:163). These are case studies that approach only a specific and well-defined local case. However, as a whole, they suggest a picture of audiovisual translation consumption at a larger scale that should be attended to.

\section{Exploring the new audiences through translation and understanding translation through new audiences}

In the media convergence, translation can exist in a space that shifts constantly between the legal and illegal sides of the media industry. Translation Studies needs to do more to understand not only how translation occurs in these spaces but also what the societal impact of these spaces ultimately is. For instance, Dwyer (2012) presented the case of ViKi, in which a nonprofessional initiative became part of the formal economy and a legal distributor of content, while Hemmungs Wirtén (2013) offers some insights into non-professional translators who go on a strike to fight against the misuse of their products. These examples show how companies can emerge from non-professional settings and how volunteers can demand rights normally granted to paid workers only; by doing so, the studies point out the blurred borders between legality and illegality. Non-professional translation operates in gray areas that are constantly redefining the roles of translators. Non-professional translators and the audiences continuously influence each other: the availability of content causes the emergence of new habits, such as binge watching, depending on what is available and accessible, and when something is not available, non- 
professional translators identify the need and try to fill the gap. Audiences do not necessarily need to choose a side; they navigate the different legal and illegal systems to have all their needs covered. Translation Studies needs to systematically analyze how this is changing translation and its role in the media convergence. In what follows, I will touch on aspects of non-professional subtitling that radically redefine or reshape the concept of translation and suggestions regarding how the phenomenon can be approached to enlarge our understanding.

Non-professional subtitling as a user activity that is profoundly embedded in the participatory culture and that comes as a piece of the media convergence puzzle offers ample possibilities for Translation Studies to widen its object of study and rely on new types of data. It opens up spaces for the exploration of the reception of translations. In a universe of immediate distribution and consumption of audiovisual products, translation extends its multifaceted role as facilitator to access knowledge and information. The expansion of non-professional subtitling (and translation) opens the discussion of theoretical aspects which are essential to understanding translation. Further, it brings with it the opportunity to use well-stablished methods, such as surveys and questionnaires, and also new digital tools to study translation and translation flows. These resources can be applied in different and complementary ways to explore the reception of non-professional subtitles and the behavior of the audiences. International plurilingual online questionnaires could help us understand what people look for when they use non-professional subtitles or subtitles distributed through the Internet. Researchers could reach agreements with non-professional subtitling communities to request people downloading the subtitles to provide information on their viewings habits and their use of the subtitles. Additionally, the distribution of subtitles over Internet means that researchers could trace the flows of the subtitles, quantify their circulation, learn about their popularity and use, the languages involved in the exchanges 
and the types of material that are more and less likely to be translated, to name but a few possibilities. The information collected from these sources could be cross-referenced with information from social media to learn more about the behavior of users and the flows of content. Tweets with geographical information would add precision to the datasets, for instance. In order to be able to use big data at this scale, Translation Studies scholars should establish interdisciplinary projects with media scholars and computer scientists. This will allow researchers to analyze the social impact of non-professional translation from an empirical, sociological and cultural perspective.

The next paragraphs describe some of the areas in which exploring the distribution and reception of non-professional subtitling can support the expansion of Translation Studies. By definition, non-professional subtitling does not fit into previous models of understanding translation. Translational activities as understood by descriptive translation studies, functionalism or Skopos theory, post-colonial studies, and even the turns that became popular in the last decade, are deeply rooted in the understanding that there is a sender of the translation and a receiver, and that there is another agent that mediates between the two of them. Having users, prosumers, create the translation for an audience to which they belong alters the existing models of translation (Cronin 2012). Thus, it requires further research and the development of models that can account for the emerging dynamics of communities in which users have turned translators. This issue touches on discussions about professionalization and ethics, but also on aspects related to our understanding of what translation is and what the social responsibility of translation, outside of the professional, is.

With the proliferation of non-professional translation practices and the popularization of translation as a social activity, translation has perhaps raised awareness among users. The 
invisibility of translation has been a reason of complaint in Translation Studies. When consuming audiovisual products through pirate networks, users need to look for subtitle files and video files separately. They need to do additional, conscious tasks that are directly related to translation, something they do not necessarily have to do when they access mainstream media. Through this, users might be made aware of the fact that translation does not simply occur, but that people are devoted to the creation of the subtitles. It is still important to examine whether this can be considered beneficial or detrimental in terms of the profession. The massive production of translations by volunteers can also lead to the denial of translation as an effort (Gambier 2016:7). Yes, translation is indeed more visible because people need to consciously look for it to access the content they want. However, at the same time, if any user-turnedtranslator can, in fact, produce a translation that is serving hundreds or thousands of other users, then why do professional translators charge for their work and, more importantly, why do we need professional translators at all?

Non-professional subtitling has facilitated the access of users to audiovisual content through piracy networks. By doing so, it has supported the emergence of new forms of engagement with audiovisual content. This includes binge watching radically changing the way in which users engage with audiovisual content, in many cases thanks to the support of nonprofessional subtitles. Users themselves recognize the value of different translation modes. A claim that surfaces often is the idea that using subtitles allows viewers to have an experience which is closer to the original (Casarini 2014b; Orrego-Carmona 2014). This reconfigures how viewers engage with content and might provide insights into the future of translation. In comparison to other forms of translation, access to non-professional subtitles and translation is easy to trace. Larger projects using big data and tracking downloads on non-professional 
translation websites can shed some light on the patterns of consumption of the audiences, as well as their preferences. Larger data sets will be at the disposal of the researchers to conduct much needed interdisciplinary and international projects to explore the reception of translated products.

New audiences engage with the content differently, and new audiovisual content has been created in a way that supports users' engagement. Committed users have specific skill sets that allow them to decode the content. These involve "consistent watching, a detail-oriented viewing approach and a memory that functions well enough to store and process the countless references to previous episodes, to other parts of the cult puzzle spread over different media, and to a considerable amount of required background knowledge" (Casarini 2014b:3). The fact that users have access to both the original and the translation at the same time creates the opportunity for them to judge the translations in those cases in which they have some level of proficiency in the original language. The understanding of translation quality is then at stake since quality might not mean the same for a translator as it does for the user, clients and, in this case, media companies (Dwyer 2012). Users have more time to engage with the translations, if they so wish, because the consumption of content is self-paced. Even if they binge watch a whole season in a matter of hours, they can pause, rewind, watch the content again, go back to previous episodes to check for consistency, etc. They are not forced to blindly trust the translation but have the power to build that trust or challenge the translation themselves and look for another version.

In a context in which translated audiovisual products are consumed as soon as they come out, translation needs to be faster. Immediacy is key for new audiences and with binge watching becoming a popular mode of consumption by part of the audience, it is something that deserves further attention. Viewers normally find it difficult to understand that non-professional subtitlers can have subtitle files ready only a couple of hours after the release when broadcasters 
commonly refer to translation as one of the reasons for delayed releases. For these highlyattached users, the good translation is the one that is available as soon as possible. This is hardly reconcilable with professional understandings of translation quality. The situation calls for a reassessment of translation processes. Active viewers' ideas should be analyzed and taken into consideration to understand what is expected from translators, and non-professional translation communities should be studied to understand how they work. This could lead to a symbiosis between professionals and non-professionals that could support media convergence. Companies like Netflix have started streamlining their production processes to produce subtitles faster. Netflix recently launched Hermes, ${ }^{11}$ an online subtitling test to find translators for its products. The campaign combines crowdsourcing strategies with traditional translator-assessment methods: everyone with a working Internet connection as well as "a background in subtitling" should be able to take the test and join Netflix's network. By understanding the needs of the viewers and the mechanisms of the non-professionals, translators could devise strategies to face the present and upcoming challenges posed by new media consumption.

\section{Final remarks}

The proliferation of non-professional translations is part of a wider digitalization of the television and film industry, and the discussion surrounding non-professional translators could benefit from framing the phenomenon more strongly within the participatory culture and the convergence discourses. By turning to analyze the behavior of the audiences and the societal impact of non-

\footnotetext{
${ }^{11}$ https://tests.hermes.nflx.io/
} 
professional translation, Translation Studies will be able to understand the wider role that translation is currently playing thanks to the changes influenced by digital technology and the participatory culture that has ensued.

Reception is one of the areas of Translation Studies that has been considered important, from a theoretical perspective (Brems \& Ramos Pinto 2013), but which has received limited empirical attention. The exploration of the flow of translations online and digital interaction of users can provide solid empirical data to test new hypotheses about translation. Large scale surveys and questionnaire, as well as big data from social media and non-professional subtitling websites, can offer valuable insights into the phenomenon. These data would not only provide information regarding issues such as power, language hegemony, and globalization but also help redefine basic concepts of translation that have been transformed by the democratization of technology and the technologization of democracy.

In general, we know little about the role of translation in developing contexts. Translation has been contextualized primarily based on the case of translation in European and other developed contexts (US, Australia, Canada). Exploring non-professional subtitling as part of the participatory culture has the potential to start shedding some light on the types of translation that occur outside of the formal economy, such as in the piracy networks. Studying the role and the impact of non-professional translation in emergent economies helps us to add another level of understanding of translation, with a more global perspective.

The new audiences, made up mostly of lurkers from online communities, have become an essential motivation for innovation and the pushing of boundaries through the participatory culture and the consolidation of transmediality. Exploring the translations that travel through the global flows of audiovisual media can provide us with a picture of the intercultural 
communication that connects users around the world. Translation Studies, as an essential

component of this ensemble, needs to establish stronger ties with the neighboring areas in media studies and converse with them in order to assess their discourses and understand itself better as part of a technologized society.

\section{References}

Anderson, Chris. 2006. The Long Tail: Why the Future of Business Is Selling Less of More. New York: Hyperion.

Ballano, Vivencio O. 2016. Sociological Perspectives on Media Piracy in the Philippines and Vietnam. Singapore: Springer.

Bold, Bianca. 2011. "The Power of Fan Communities: An Overview of Fansubbing in Brazil." Tradução em Revista 11 (2): 1-19.

Brems, Elke, and Sara Ramos Pinto. 2013. "Reception and Translation." In Handbook of Translation Studies, ed. by Yves Gambier and Luc van Doorslaer, vol. 4, 142-147. Amsterdam and Philadelphia: John Benjamins Publishing Company.

Bruns, Axel. 2009. "The User-Led Disruption: Self-(Re)Broadcasting at Justin.tv and Elsewhere." In Proceedings of the 7th European conference on interactive TV and video, Leuven, Belgium, ed. by Dirk de Grooff, 87-90. New York: ACM.

Casarini, Alice. 2014a. The Perception of American Adolescent Culture Through the Dubbing and Fansubbing of a Selection of US Teen Series from 1990 to 2013. PhD thesis, Università di Bologna, Forlì, Italy.

Casarini, Alice. 2014b. "Viewership 2.0: New Forms of Television Consumption and their Impact on Audiovisual Translation." inTRAlinea Special Issue: Across Screens Across Boundaries: n.p.

Castells, Manuel, and Gustavo Cardoso (eds). 2013. Piracy Cultures: How a Growing Portion of the Global Population Is Building Media Relationships Through Alternate Channels of Obtaining Content. Los Angeles: USC Annenberg Press.

Chang, Pin-Ling. 2017. "Chinese Fansubbing of US TV Show "The Big Bang Theory": From Ideological Perspectives.” In Non-Professional Subtitling, ed. by David Orrego-Carmona and Yvonne Lee, 233-258. Newcastle upon Tyne: Cambridge Scholars Publishing.

Chaume, Frederic. 2013. "The Turn of Audiovisual Translation: New Audiences and New Technologies." Translation Spaces 2: 105-123.

Chu, Donna S. 2012. "Fanatical Labor and Serious Leisure: A Case of Fansubbing in China." In Frontiers in New Media Research (Routledge Research in Information Technology and Society), ed. by Francis L. Lee, Louis Leung, Jack L. Qiu and Donna S. C. Chu, 259-277. Hoboken: Taylor and Francis.

Cronin, Michael. 2012. Translation in the Digital Age. London, New York: Routledge. 
Danaher, Brett, Samita Dhanasobhon, Michael D. Smith and Rahul Telang. 2010. "Converting Pirates Without Cannibalizing Purchasers: The Impact of Digital Distribution on Physical Sales and Internet Piracy." Marketing Science 29 (6): 1138-1151.

Denison, Rayna. 2011. "Anime Fandom and the Liminal Spaces Between Fan Creativity and Piracy.” International Journal of Cultural Studies 14: 449-466.

Díaz Cintas, Jorge, and Pablo Muñoz Sánchez. 2006. "Fansubs: Audiovisual Translation in an Amateur Environment." JoSTrans, The Journal of Specialised Translation 6: 37-52.

Duraner, Jarmin E., Gülfer Tunali and Müge Işıklar Koçak. 2017. "Fansubbers as Cultural Agents for Korean Dramas." In Non-Professional Subtitling, ed. by David Orrego-Carmona and Yvonne Lee, 145-170. Newcastle upon Tyne: Cambridge Scholars Publishing.

Dwyer, Tessa. 2012. "Fansub Dreaming on ViKi: "Don't Just Watch but Help When You Are Free"." The Translator 18 (2): 217-243.

Fernández Costales, Alberto. 2012. "Collaborative Translation Revisited: Exploring the Rationale and the Motivation for Volunteer Translation." Forum 10 (1): 115-142.

Gambier, Yves. 2016. "An Obsession: .com Between the Rocky Shores of Myth and the New Balance of Powers." Studies About Languages 27: 5-19.

Gambier, Yves, and Sara Ramos Pinto. 2016. "Introduction." Target 28 (2): 185-191.

Hemmungs Wirtén, Eva. 2013. "Swedish Subtitling Strike Called Off! Fan-to-Fan Piracy, Translation, and the Primacy of Authorisation." In Amateur Media: Social, Cultural and Legal Perspectives, ed. by Dan Hunter, Ramon Lobato, Megan Richardson and Julian Thomas, 125-136. Abingdon, New York: Routledge.

Jenkins, Henry. 1992. Textual Poachers: Television Fans and Participatory Culture. (Studies in culture and communication). New York: Routledge.

Jenkins, Henry. 2006a. Convergence Culture: Where Old and New Media Collide. New York: New York University Press.

Jenkins, Henry. 2006b. Fans, Bloggers, and Gamers: Exploring Participatory Culture. New York: New York University Press.

Jiménez-Crespo, Miguel A. 2017. Crowdsourcing and Online Collaborative Translations. Amsterdam and Philadelphia: John Benjamins Publishing Company.

Karaganis, Joe (ed). 2011a. Media Piracy in Emerging Economies. New York: Social Science Research Council.

Karaganis, Joe. 2011b. "Rethinking Piracy." In Media Piracy in Emerging Economies, ed. by Joe Karaganis, 1-74. New York: Social Science Research Council.

Kosnik, Abigail de. 2010. Piracy Is the Future of Television. http://boletines.prisadigital.com/piracy_future_television-full.pdf, Accessed November 27, 2016.

Luczaj, Kamil, Magdalena Holy-Luczaj and Karolina Cwiek-Rogalska. 2014. "Fansubbers: The Case of the Czech Republic and Poland.” Journal of Comparative Research in Anthropology and Sociology - Compaso 5 (2): 175-198.

Massidda, Serenella. 2012. The Italian Fansubbing Phenomenon. PhD Thesis, Università degli Studi di Sassari, Sassari, Italy.

Matrix, Sidneyeve. 2014. "The Netflix Effect: Teens, Binge Watching, and On-Demand Digital Media Trends." Jeunesse: Young People, Texts, Cultures 6 (1): 119-138. 
Mattelart, Tristan. 2013. "Audiovisual Piracy, Informal Economy, and Cultural Globalization." In Piracy Cultures: How a Growing Portion of the Global Population Is Building Media Relationships Through Alternate Channels of Obtaining Content, ed. by Manuel Castells and Gustavo Cardoso, n.p. Los Angeles: USC Annenberg Press.

Mendes Moreira De Sa, Vanessa. 2014. "The Collaborative Production of Amateur Subtitles for Pirated TV Shows in Brazil.” In Piracy: Leakages from Modernity, ed. by James Arvanitakis and Martin Fredriksson, 285-306. Sacramento, California: Litwin Books.

Mittell, Jason. 2009. To Spread or to Drill? https://justtv.wordpress.com/2009/02/25/to-spreador-to-drill/, Accessed November 10, 2017.

MUSO. 2016. MUSO's Global Film \& TV Piracy Insight Report 2016 Released. https://www.muso.com/magazine/musos-global-film-tv-piracy-report-2016-released/

Nielsen, Jakob. 2006. The 90-9-1 Rule for Participation Inequality in Social Media and Online Communities. http://www.nngroup.com/articles/participation-inequality/, Accessed November 10, 2017.

Olohan, Maeve. 2014. "Why Do You Translate? Motivation to Volunteer and TED Translation." Translation Studies 7 (1): 17-33.

Orrego-Carmona, David. 2014. "Subtitling, Video Consumption and Viewers: The Impact of the Young Audience.” Translation Spaces 3: 51-70.

Orrego-Carmona, David. 2015. The Reception of (Non)Professional Subtitling. PhD thesis, Universitat Rovira i Virgili, Tarragona, Spain.

Orrego-Carmona, David. 2016a. "A Reception Study on Non-Professional Subtitling: Do Audiences Notice Any Difference?” Across Languages and Cultures 17 (2): 163-181.

Orrego-Carmona, David. 2016b. "Internal Structures and Workflows in Collaborative Subtitling." In Non-professional Interpreting and Translation in the Media, ed. by Rachele Antonini and Chiara Bucaria, 211-230. Peter Lang.

Orrego-Carmona, David, and Simon Richter. Forthcoming. "Tracking the Distribution of NonProfessional Subtitles to Study New Audiences.".

Pérez-González, Luis. 2010. "'Ad-Hocracies' of Translation Activism in the Blogosphere: A Genealogical Case Study." In Text and Context: Essays on Translation \& Interpreting in Honour of Ian Mason, ed. by Mona Baker, Maeve Olohan and María Calzada Pérez, 259287. Manchester, UK, Kinderhook, NY: St. Jerome Pub.

Pérez-González, Luis. 2012. "Co-Creational Subtitling in the Digital Media: Transformative and Authorial Practices.” International Journal of Cultural Studies 16 (1): 3-21.

Pérez-González, Luis. 2013. "Amateur Subtitling as Immaterial Labour in Digital Media Culture: An Emerging Paradigm of Civic Engagement." Convergence: The International Journal of Research into New Media Technologies 19 (2): 157-175.

Strangelove, Michael. 2015. Post-TV: Piracy, Cord-Cutting, and the Future of Television. (Digital futures). Toronto, Buffalo, London: University of Toronto Press.

Sun, Na, Patrick P.-L. Rau and Liang Ma. 2014. "Understanding lurkers in online communities: A literature review." Computers in Human Behavior 38: 110-117.

Tapscott, Don \& Anthony D. Williams. 2006. Wikinomics: How Mass Collaboration Changes Everything. New York: Portfolio. 
The Nielsen Company. 2016. Video on Demand: How the Worldwide Viewing Habits Are Changing in the Evolving Media Landscape.

http://www.nielsen.com/content/dam/nielsenglobal/eu/docs/pdf/Nielsen-global-video-ondemand.pdf, Accessed May 13, 2017.

Tian, Yuan. 2011. Fansub Cyber Culture in China. MA dissertation, Georgetown University. Yang, Xue, Guoxin Li and Songshan S. Huang. 2016. "Perceived Online Community Support, Member Relations, and Commitment: Differences Between Posters and Lurkers." Information \& Management 54 (2): 154-165. 